\title{
CORRIGENDA
}

\section{Significant variation in haplotype block structure but conservation in tagSNP patterns among global populations}

Sheng Gu, Andrew J Pakstis, Hui Li, William C Speed, Judith R Kidd and Kenneth K Kidd European Journal of Human Genetics (2007) 15, 818; doi:10.1038/sj.ejhg.5201862

Correction to: European Journal of Human Genetics (2007)

15, 302-312. doi:10.1038/sj.ejhg.5201751

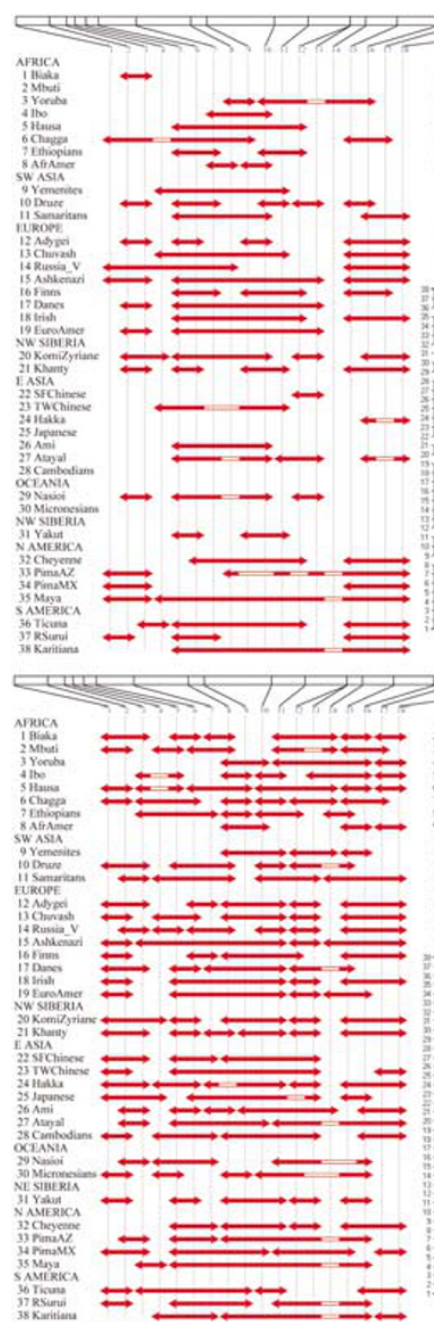

PAH
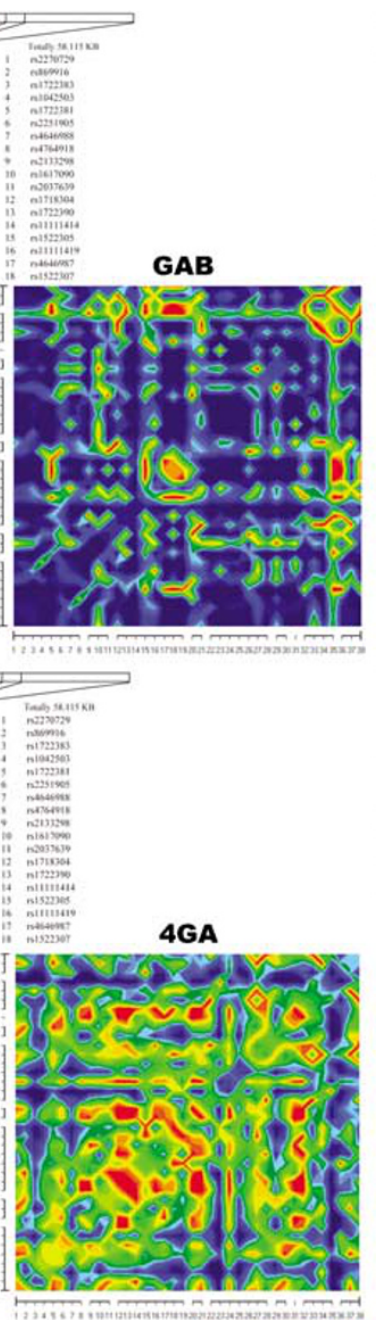

The authors have noticed an error in Figure 3 of the above paper. The KR2 block plot was duplicated as the SPI plot, which was not shown. The correct figure is shown below.

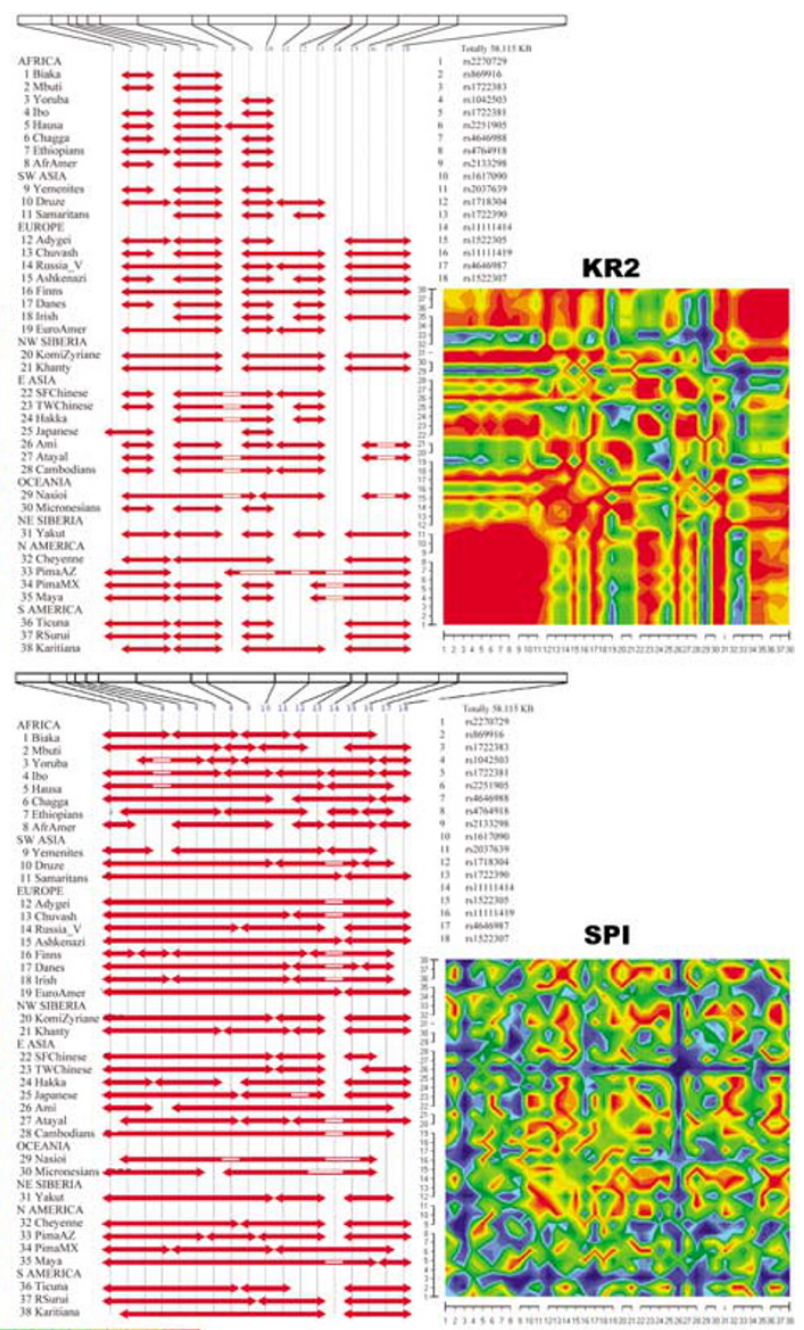

